\title{
Reproductive behavior of the oil-collecting bee Epicharis dejeanii (Apidae: Centridini)
}

\author{
Enderlei Dec, Felipe Vivallo \\ Laboratório de Hymenoptera (HYMN); Departamento de Entomologia; Museu Nacional, Universidade Federal do Rio \\ de Janeiro, Quinta da Boa Vista - São Cristóvão, Rio de Janeiro, RJ 20940-040, Brazil
}

Received 27 April 2020 - Revised 5 October 2020 - Accepted 28 October 2020

\begin{abstract}
In solitary bees, monandry is common in several species. Post-copulation strategies exerted by males to prevent females from mating with other males are known and vary between species. We studied a population of Epicharis dejeanii (Centridini) analyzing the reproductive aspects. The average mating time and the behavior of the couples were observed. Males performed synchronized movements of the legs and antennae in addition to vibrations that generated a loud sound. The females remained static, starting movements with their legs to finish the mating after approximately $50 \mathrm{~s}$. During the mating, the females' sting was kept exposed. The males inserted the aedeagus into the female's genital opening but kept out the genitalia. The male's post-copulatory behavior seems to be performed simultaneously during mating.
\end{abstract}

mating behavior / monandry / post copulation / solitary bees

\section{INTRODUCTION}

Reproductive strategies are known in several animal taxa (Brockmann 2001), and they are associated with the evolutionary success of the species and with the individual fitness of the specimens of each sex. Not only the mate, but also the previous and posterior stages (pre- and post-copulation) are important for the individual's reproductive success. Thus, these events are articulated by males whose objective is to fertilize females, increasing their reproductive success.

Several strategies are adopted in monandrous bees in which females copulate only once, and the

Corresponding author: E. Dec, enderlei@hotmail.com Manuscript editor: James Nieh

Contributions: The field data collection were performed by ED; Both the authors analyzed the data, wrote and revised the manuscript; The figures were designed by FV. dispute between males for mating can be quite aggressive. Alcock (1977) observed that in the solitary bee Centris pallida Fox, the larger males exert dominance over the virgin females. Variations in body size between males have also been reported in others bee species, such as Hylaeus alcyoneus (Erichson) (Colletidae) (Alcock and Houston 1987), Perdita portalis Timberlake (Andrenidae)(Danforth 1991), P. texana Timberlake (Danforth and Neff 1992), Amegilla dawsoni (Rayment)(Houston 1991), and Ptilothrix fructifera(Holmberg) (Apidae) (Oliveira and Schlindwein 2010). In the anthophorine bee $A$. dawsoni, the dispute for mating generates fights between males that result in the death of many of them, including of some females (Alcock 2013). In other species of solitary bees, two male strategies have been recorded: some of them patrol the nesting area while others patrol the flowers visited by the virgin females (Wcislo 1992; Neff and Simpson 1992, 1997; Alcock et al. 2010; Pina et al. 2020). 
Mating in some populations of solitary bees can also be very limited due the seasonality. The availability of the virgin females can be ephemeral, which increases the dispute between males. During the cold seasons (autumn and winter), adults are not present and the immatures are in diapause (Michener 2007). In this period, there is a reduction of metabolic activity (Belozerov 2009), a strategy that allows the individuals to remain safe until the return of favorable climatic conditions for their complete development (Danks 2007; Michener 2007). The adult stage is relatively short which is used to reproduce, being often difficult to detect them during mating.

The reproductive biology of the oil-collecting bees of the genus Epicharis is poorly studied. Epicharis dejeanii is a species with large distribution range; however, the information about its behavioral aspects is not completely known. Hiller and Wittmann (1994) recorded the male's activity that patrolled in an aggregation area, the density of individuals, and the approach of the males on virgin females to mate. Additional information on reproductive biology of the species such as the duration of the mating, the behavior of males and females during the mating, and the male's strategy to patrolling over the flowers visited by females was confirmed by Pina et al. (2020). We conducted a study with the aim to recognize the different steps of the mating behavior and presented new details on the male and female's behavior during the mating. A new male strategy to access virgin females was confirmed in this study. The results here presented complement those published by Hiller and Wittmann (1994) and Pina et al. (2020) on this species.

\section{MATERIALS AND METHODS}

A population of Epicharis dejeanii was studied between November 2017-January 2018 and November 2018-December 2018. The aggregation was located in an uncovered area with sandy and flat soil $\left(120 \mathrm{~m}^{2}\right)$ at Ilha das Flores, Babitonga's Bay, north coast of Santa Catarina state, southern Brazil (- $\left.26^{\circ} 15^{\prime} 20^{\prime \prime} \mathrm{S},-48^{\circ} 41^{\prime} 14^{\prime \prime} \mathrm{W}\right)$. This island contains approximately 9 ha and is formed by areas of Restinga and arboreal vegetation of Dense Ombrophilous Forest. However, there are several residences with garden areas and herbaceous ruderal vegetation next to them. According to Köppen (1948), the climate of the region is classified as "Cfa" (warm and humid subtropical) with well-defined seasons and without periods of drought throughout the year.

The samplings were conducted from 6:30 am to 5:00 pm which represent the period of activity of females (Hiller and Wittmann 1994; Dec and Vivallo 2019). Between these intervals, the temperature was registered every hour using a field thermometer. Mating behavior was directly observed and recorded digitally for posterior behavioral analysis and description. Newly mated females were immediately captured with entomological net and placed with other males in a small clear acetate plastic box to check the monandry/ polyandry $(n=5)$. During this procedure, there was no manual contact with the bees (males and females). The couples were captured, the males were released, and the females were transferred from the entomological net directly to the plastic box. A similar test to check that feature was done separating females during the first seconds of the mating and offered to other male previously maintained in the plastic box. To separate the couples, the metal ring of the entomological net was placed between the bees keeping the male outside and the female inside the net, interrupting genital contact and forcing the separation of the bees.

Soil traps measuring $50 \mathrm{~cm} \times 50 \mathrm{~cm} \times 15 \mathrm{~cm}$ were used to capture newly emerged females from their nests. These cages covered with "voile fabric" were distributed randomly in the aggregation area to get virgin females. The sound pulses emitted during mating were recorded using Wavosaur (ver. 1.2.0.0) software.

\section{RESULTS}

\subsection{Emergence and flight activities}

Immediately after the females emerged, they made a circular flight over the nest, to then fly in another direction. On the other hand, the males during their emergence stayed a few seconds at the entrance of the nest and later flew away quickly from it. 
During the first days of observation, only males were present and females appeared progressively after the second week, which indicates that the species is protandric. The females' flight activities started daily around 6:40 am while males arrived always after 8:30 am. Females flew on sunny, cloudy, or light rain days while males only appeared in the aggregation area on sunny days. When the clouds covered the sun, the males also left the area, but they returned with the reappearance of the sun. Days with temperatures below 20 ${ }^{\circ} \mathrm{C}$ drastically reduced the number of males in the area. In the nesting site, their flights were low, no more than $1 \mathrm{~m}$ above the ground and generating a characteristic sound, being easily differentiated from the females. During the mornings and approximately until 1:30 $\mathrm{pm}$, they patrolled the area making quick and random flights looking for virgin females to mate. After visually identifying a bee in flight, the males approached to it for apparently chemical recognition and every day, some males were persecuted by several others during a short period of time. When a male confirmed the presence of a virgin female, he persecuted and collided with her in the air. The collisions were prompt and apparently aggressive. The female was knocked over to the ground and immediately the male, as well as others present in the area landed on her to try to mate.

Sometimes, a group of males were observed on the ground digging intensely the soil. The activity began with only one male digging and in a few seconds others also accumulated near him creating a cluster, sometimes with more than ten specimens. Apparently, the first male would be responding to some chemical signal of a virgin female underneath the ground. Although this situation was observed several times, only once the emergence of a female was observed (Online Resource 1).

\subsection{Mating behavior}

In all approaches observed $(n=7)$, more than one male landed on the female creating a dispute over her to get the genital contact (Figure 1a, b). In addition of the seven approaches in the air, others nine were observed when there was already the cluster of males on the female or only the couple, totaling 16 matings. No agonistic behavior was observed between males; they only overlapped each other, remaining all of them over the female (Figure 1a, b). Some males performed repetitive protraction and retraction movements of the genital capsule independent of their positioning apparently stimulated by the odor of the female.

Despite several males landed on the female, only one performed the mating. The male who copulated with the female was the one who was correctly positioned over her to perform the genital contact. That specimen was not necessarily the male who dropped her. Once the mating was initiated, the other males got out (Figure 1c), remaining only the couple (Figure 1d). In two cases, the couple was separated during the mating after another male arrived. In both cases, the female flew away and we do not know if she copulated again.

To achieve adjusting of his genitalia, the male attached the claws of his forelegs in the female's tegulae. The male's middle and hind legs made synchronized movements with the male's antennae (Figure 2a, b). In each metasomal contraction, the legs and antennae made fast and repeated movements. The antennae moved rapidly forward and simultaneously the middle legs tapped laterally on the female's mesosoma. The hind legs were rubbed on the ventral surface of the female's metasoma from front to back. The wings remained in the resting position. Eventually, the antennae of both specimens touched each other (Figure 2b). In each male's metasoma, contraction sounded a strong buzz (Figure 3). This sound, as well as the pattern behavior, was performed in all matings observed.

All matings occurred on the ground, except one which the female remained attached by her mandibles in an herbaceous plant stem close to the ground. The mating lasts, on average, $1 \min 35 \mathrm{~s}( \pm 16 \mathrm{~s}, n=7)$, but after $50 \mathrm{~s}( \pm$ $8 \mathrm{~s}, n=7)$, the females initiated lifting movements of her middle and hind legs attempting to push the male away (Figure 2c, d). Despite the attempt, in all observed mating, such strategy was not effective. The matings observed were always in the morning when the females returned from the field (Figure 4). Therefore, some emergences of females must have occurred before the arrival of the males in the 

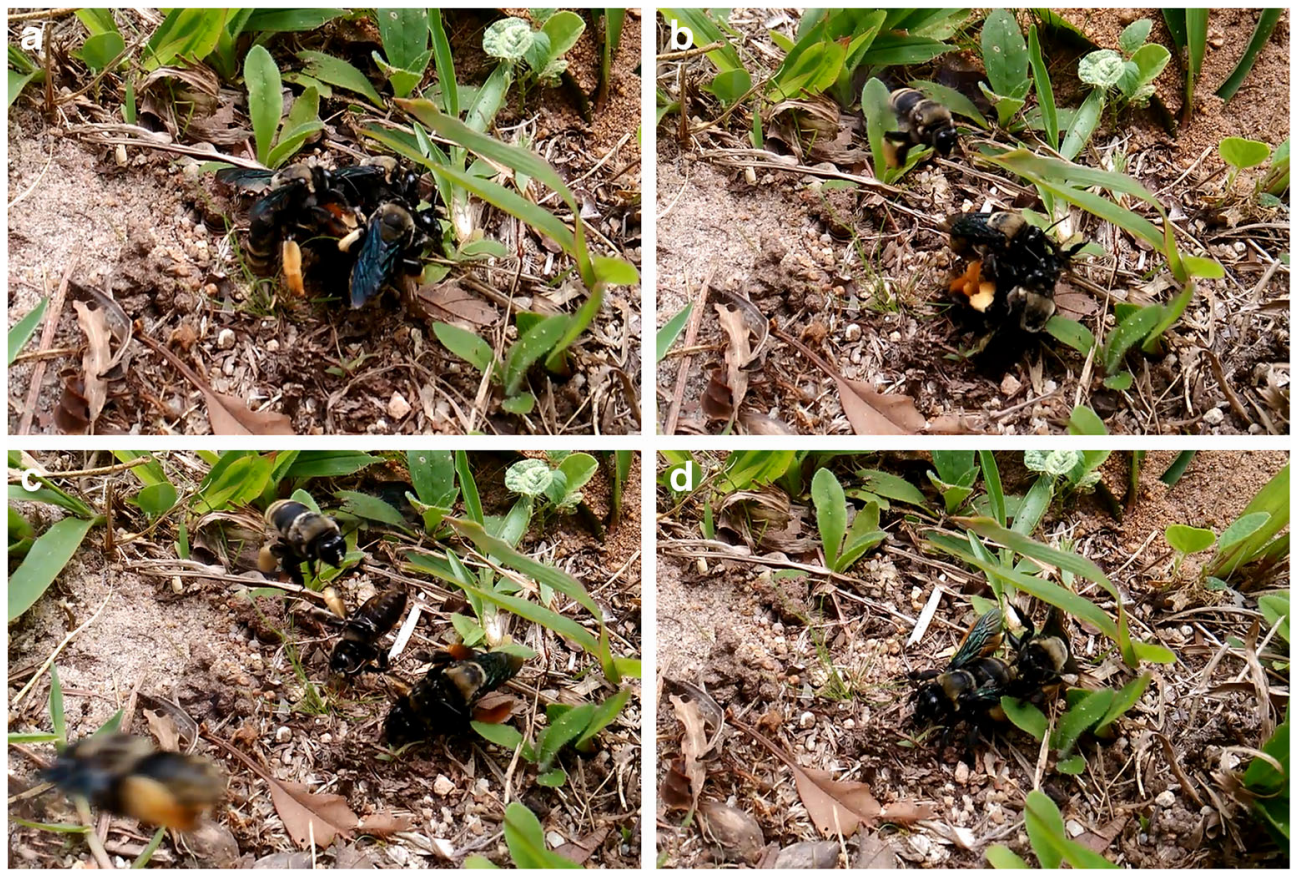

Figure 1. Mating behavior of Epicharis dejeanii . a Group of males trying to copulate with a female. b Males flying away when they do not reach the right position for mating. $\mathbf{c}$ The group of males dissolves. $\mathbf{d}$ The male that reached the right position starts mating.

aggregation area, allowing the females to make one or more flights to feed before the mating. We recorded two interesting behaviors during mating: 1 -females kept the sting facing outwards, laterally; 2-males kept the genitalia outside the female's body and only the aedeagus was introduced into her (Figure 2e). After mating, males frequently perform some metasomal contractions before flying (Figure 2f).

Other four matings were interrupted during the first seconds, and the females were placed in acetate plastic box with other male, but no new copulations were observed. In the soil traps, only two females emerged. Males that flew in the area did not land on the traps to try to reach them. The females were placed with different males, in the plastic box, and surprisingly, they showed no interest in copulating.

\section{DISCUSSION}

The approach of males upon females was similar to that registered by Hiller and Wittmann
(1994) and Pina et al. (2020). When a male detects a virgin female, he flies over her and knocked down in order to initiate the mating. Apparently, visual stimulation is an important and primary factor in males to search females. Eventually, some males approached black seeds that were found on the ground coming from a nearby tree, which reinforces that in the first time, they were strongly attracted by visual rather than chemical stimuli.

The virgin females whose were approached by males always returned without floral resources on their scopaes, suggesting flights for their own food. The females captured in the soil traps also emerged before the males arrived in the area. These females as well as those collected during or immediately after mating did not exhibit interest in the males or vice versa when they were placed in the plastic acetate box.

Although many studies suggest the monandry in Centridini, no experiments have been cited to evaluate this statement. Post-insemination strategies to ensure mating success are diversified 

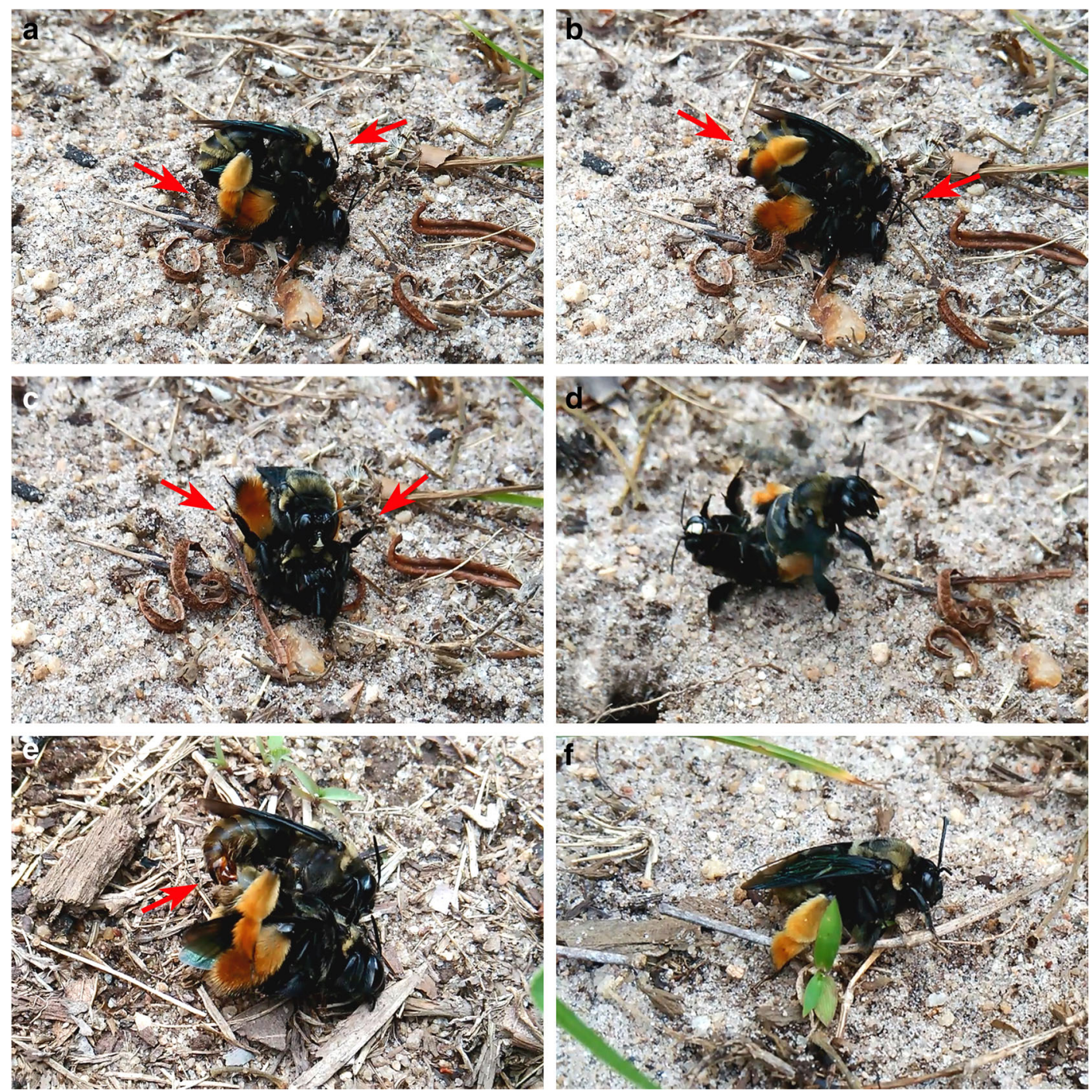

Figure 2. Sequence of the mating of Epicharis dejeanii. a, b The couple in mating position (male above). Red arrows indicate movements of male's legs and antennae. c, d The female raises her middle and hind legs (red arrows) to finish the mating and to scape from the male. e Male's genitalia (red arrow) outside the female's body during mating. F: Male performing metasomal contractions after mating.

among males of different insects, for example, prolongation of genital contact after termination of insemination, plugs left in the genital opening of the female, persistence of physical contact after mating, or monitoring of the male on the female (Alcock 1994, 1997).

Rutowski and Alcock (1980) observed that post-copulatory genital contact in the andrenid bee Calliopsis (Nomadopsis) puellae(Cockerell) (Hymenoptera: Andrenidae) can last up to $40 \mathrm{~min}$.
However, Alcock (1994) proposed that the chances of search for other sexual partners may be reduced in some species where the female can be properly stimulated by the male. Alcock and Buchmann (1985) observed that when separated from their mate before the onset copulatory courtship, the females were more likely to mate a second time than were females who received post-copulatory courtship. These same authors recorded the post-copulation in Centris pallida 


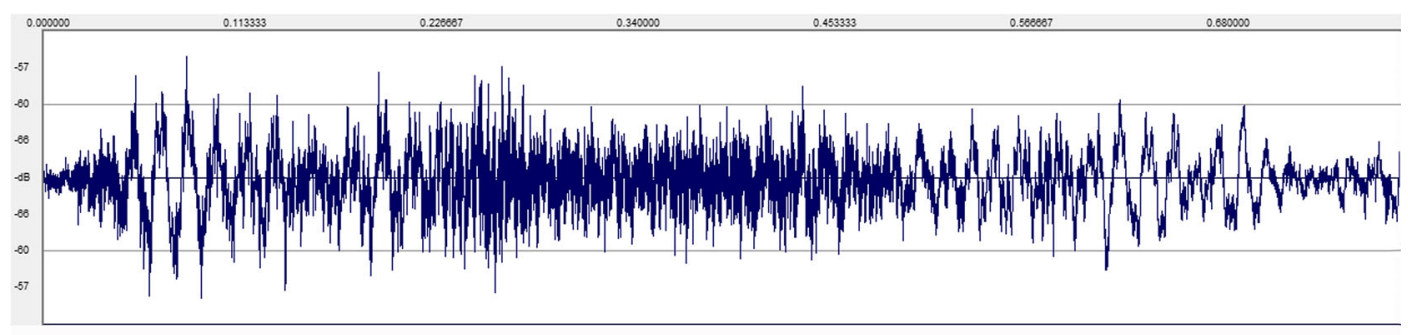

Figure 3. Sound pulse emitted during a male's metasomal contraction synchronized with the movement of his antennae during copulation. Apparently, each contraction would correspond to sperm release.

and demonstrated that females not stimulated by male (acoustically and physically) were still willing to further mating. The physic stimulus involving the movements of antennae of the male as well as the friction and beating of the legs was similar to those already recorded by Pina et al. (2020) and also observed in the present study in Epicharis dejeanii.

During the mating, it was observed that the male performs specific movements. During each male's metasoma contraction sounded a strong buzz which corresponds to sperm release (Toro and Riveros 1998). The ventral surface of the male's hind legs rubbed on the sterna of the female since the first moment in which the genital contact occurs was also observed by Pina et al. (2020), and it could be the stimulus responsible for triggering physiological changes in the female that makes the female no longer sexually available to copulate with other partners. Simmons et al. (2003) verified that females of some bees produce cuticular hydrocarbons different from those generated by virgin females. This suggests that males could recognize virgin females by a chemical signal since, morphologically, there is no distinction between virgin and non-virgin females. The behavior of females mating with only one male is common in solitary bees (Raw 1992). Thus, such post-copulation strategies in solitary bees would justify this claim. However, studies involving reproductive behavior remain scarce in the literature.

In the present study, females newly copulated were placed individually with other males which

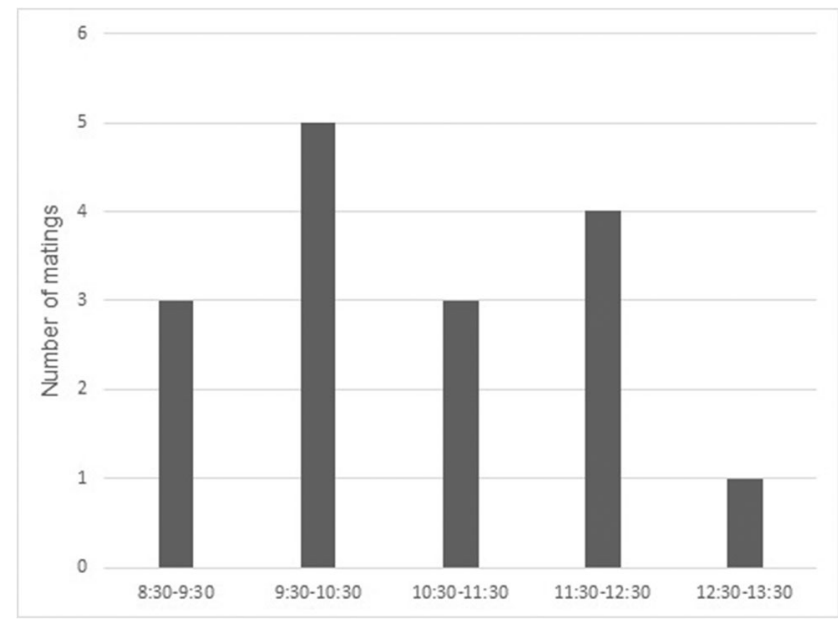

Figure 4. Number of matings recorded each hour during the study at Ilha das Flores, Babitonga's Bay, Santa Catarina state. 
did not exhibit any interest on them. Likewise, those that were separated from the males during the initial seconds of mating also did not have interest with other males. Thus, it is possible that the "attractive odor" of virgin female does not finish with the end of mating, but from the beginning. This suggests that in this species, the postcopulation step is performed concomitantly with mating. A similar ritual behavioral was registered in males of the megachilid bee Osmia bicornis ( Linnaeus) (Hymenoptera: Megachilidae). However, in that species, the males performed this sequence after mating (Seidelmann 2014). The group of males that were formed on the virgin female when she was dropped on the ground quickly ended as soon as one of the males starts the mating, remaining only the couple. This behavior also reinforces the hypothesis that the attractive odor of the virgin female ends at the beginning of mating. The behavior of many males forming a cluster on a virgin female has also been recorded in Centris burgdorfi Friese (Sabino et al. 2017), Epicharis bicolor Smith (Rocha-Filho et al. 2008), E. nigrita Friese (Martins et al. 2019), as well as in other populations of $E$. dejeanii (Hiller and Wittmann 1994; Pina et al. 2020).

Another strategy adopted by males in some species, including centridine bees, is to dig the soil in search of virgin females. In Centridini, this behavior has been recorded in Centris pallida ( Alcock 2009) and C. burgdorfi (Sabino et al. 2017). In our study were registered groups of males digging the soil, but only once occurred an emergence of a female in the same instant. Despite our record, Pina et al. (2020) claimed that this strategy did not occur in the population studied by them.

Hiller and Wittmann (1994) registered groups of males creating flight corridors in the way used by the females to obtain the floral resources, while Pina et al. (2020) registered males patrolling the plants which were used by females. In the present study, we observed females collecting nectar in Canavalia bonariensis Lindl. (Fabaceae) and oil in Stigmaphyllon ciliatum (Lam.) A. Juss. (Malpighiaceae). Both species are climbing plants, rarely found in the edge of the forest. We believe that the main food resources of these bees occur in the forest canopy, and, therefore, we were not able to register males patrolling on flowers.

Although a couple of studies carried out in southern Brazil on $E$. dejeanii have already been published (see Hiller and Wittmann 1994; Pina et al. 2020), their results are somewhat different when compared with those presented here. These differences indicate the existence of some plasticity and behavioral variations among the populations studied, which could be related to the local environmental conditions. New research that focused on the reproductive behavior of this species developed in other locations could provide new data on the behavioral diversity of this species.

\section{GENERAL SUMMARY}

Females of solitary bees generally copulate once in her life. Males have developed postcopulation strategies to avoid sperm competition with other males, ensuring the transmission of their genetic material through the paternity. These strategies vary between different species, such as prolongation of genital contact after termination of insemination, plugs left in the genital opening of the female, persistence of physical contact after mating, or monitoring of the male on the female.

In order to understand the behavior of males and females of the oil-collecting bee Epicharis dejeanii, we monitored the activities of this species during the months when adults are reproductively active in an island population in southern Brazil. We observed how males patrol the females' nesting area, how they approach the females, and how they both behave during the mating.

During the copulation, males rub the female's metasoma with their legs which could correspond to a stimulus that influence the females to be sexually unattractive to other males. Mating extends for approximately 1 ' $35^{\prime \prime}$, and the females signal the end of the mating trying to push the males away from them.

We captured some females after mating and placed them in a plastic box with another male, but no new mating occurred. Other captured females were separated from the male during the first seconds of mating and placed with another male, but new mating did not happen either. 
We confirm that this species is monandric, that is, females copulate only once, and we suggest that the male's behavior during mating is a mixture of copulation and post-copulation behavior which induce the female to be unattractive to other males.

Supplementary Information The online version contains supplementary material available at https://doi.org/10.1007 /s13592-020-00825-7.

\section{ACKNOWLEDGMENTS}

We thank the Coordenação de Aperfeiçoamento de Pessoal de Nível Superior (CAPES) for providing a Ph.D. scholarship to the first author; to the area's owners Mr. Nei Osvaldo Silva and Mr. Nivaldo Jose da Silva, and to the island residents Mr. Paulo Kolombesky and his wife Mrs. Marli T. Kolombesky for their support. We also thank Vanessa Feretti by the preliminary information about the location of these bees. This paper is part of the SIGMA project no. 21565MN/UFRJ and the contribution number 56 from the HYMN.

\section{DATA AVAILABILITY}

The authors declare that the data supporting the findings of this study are available within the article (and its supplementary information files). Additional data that support the findings of this study are available from the corresponding author upon request.

Comportement reproducteur de l'abeille collectrice d'huile Epicharis dejeanii (Apidae: Centridini)

comportement d'accouplement / post copulation / abeilles solitaires

Reproduktionsverhalten der Öl sammelnden Biene Epicharis dejeanii (Apidae: Centridini)

Paarungsverhalten/ Post-Kopulation/ Solitärbienen

\section{REFERENCES}

Alcock J. (1994)Post-insemination associations between males and females in insects: The mate-guarding hypothesis, Annu. Rev. Entomol. 39, 1-21.

Alcock J. (1997) Competition from large males and the alternative mating tactics of small males of Dawson's burrowing bee (Amegilla dawsoni) (Apidae, Apinae, Anthophorini), J. Insect Behav. 10, 99-113.

Alcock J. (2009) Animal behavior: An evolutionary approach (9th ed.). Sinauer Associates Publishers, Sunderland, MA.

Alcock J. (2013) Sexual selection and the mating behavior of solitary bees, Adv. Stud. Behav. 45, 1-48.

Alcock J., Buchmann S.L. (1985) The significance of postinsemination display by male Centris pallida (Hymenoptera: Anthophoridae), Z. Tierpsychol. 68, 231243.

Alcock J., Houston T.F. (1987) Resource defense and alternative mating tactics in the banksia bee, Hylaeus alcyoneus (Erichson), Ethology 76, 177-188.

Alcock J., Bailey, W.J., Simmons, L.W. (2010) The mating system of Amegilla (Asarapoda) paracalva Brooks (Hymenoptera: Apidae), J. Insect Behav. 23, 69-79.

Belozerov V.N. (2009) New aspects in investigations of diapause and non-diapause dormancy types in insects and other arthropods, Entomol. Rev. 89, 127-136.

Brockmann H.J. (2001) The evolution of alternative strategies and tactics, Adv. Stud. Behav. 30, 1-51.

Danforth B.N. (1991) The morphology and behavior of dimorphic males in Perdita portalis (Hymenoptera, Andrenidae), Behav. Ecol. Sociobiol. 29, 235-247.

Danforth B.N., Neff, J.L. (1992) Male polymorphism and polyethism in Perdita texana (Hymenoptera, Andrenidae), Ann. Entomol. Soc. Am. 85, 616-626.

Danks H.V. (2007) The elements of seasonal adaptations in insects, Can. Entomol. 139 (1), 1-44.

Dec E., Vivallo F. (2019) Nesting biology and immature stages of the oil-collecting bee Epicharis dejeanii (Apidae: Centridini). Apidologie. 50 (5), 606-615. https://doi.org/10.1007/s13592-019-00673-0.

Hiller B., Wittmann, D. (1994) Seasonality, nesting biology and mating behaviour of the oil-collecting bee Epicharis dejeanii (Anthophoridae, Centridini), Bioc. 2, 107-124.

Houston T.F. (1991) Ecology and behavior of the bee Amegilla (Asaropoda) dawsoni (Rayment) with notes on a related species (Hymenoptera: Anthophoridae), Rec. West Aust. Mus. 15, 591-609.

Köppen W. (1948) Climatología: con un estudio de los climas de la tierra. México: Fondo de Cultura Económica, pp. 478.

Martins C.F., Neto V.I.S., Cruz R.D.M. (2019) Nesting biology and mating behavior of the solitary bee Epicharis nigrita (Apoidea: Centridini), J. Apic. Res. 58, 1-11. https://doi.org/10.1080/00218839.2019.1584963

Michener C.D. (2007) The bees of the world, (2nd edn.). Baltimore, John Hopkins University Press.

Neff J.L., Simpson B.B. (1992) Partial bivoltinism in a ground-nesting bee: the biology of Diadasia rinconis in Texas (Hymenoptera, Anthophoridae), J. Kansas Entomol. Soc. 65, 377-392.

Neff J.L., Simpson B.B. (1997) Nesting and foraging behavior of Andrena (Callandrena) rudbeckiae 
Robertson (Hymenoptera: Apoidea: Andrenidae) in Texas. J. Kansas Entomol. Soc. 70, 100-113.

Oliveira R., Schlindwein C. (2010) Experimental demonstration of alternative mating tactics of male Ptilothrix fructifera (Hymenoptera, Apidae), Animal Behav. 80, 241-247.

Pina W.C., Souza-Chibatta L., Uemura N., Gobatto A.L., Freiria G.A., Sofia S.H. (2020) Male strategies and mating behavior in the Neotropical bee Epicharis (Anepicharis) dejeanii (Apidae: Centridini), J. Apic. Res. 1-10. https://doi.org/10.1080/00218839.2020.1733197.

Raw A. (1992) Mate searching, population size and nest site requirements of two univoltine solitary bees of genus Epicharis (Hymenoptera, Anthophoridae) in Brazil, Entomologist 111, 1-9.

Rocha-Filho L.C., Silva C.I., Gaglianone M.C., Augusto S.C. (2008) Nesting behavior and natural enemies of Epicharis (Epicharis) bicolor Smith 1854 (Hymenoptera Apidae), Tropic. Zool. 21, 227-242.

Rutowski R.L., Alcock J. (1980) Temporal variation in male copulatory behavior in the solitary bee Nomadopsis puellae (Hymenoptera: Andrenidae), Behaviour 73, 175-187.

Sabino W.O., Silva C.I., Alves-dos-Santos I. (2017) Mating system and sleeping behaviour of the male and female
Centris (Paracentris) burgdorfi Friese (Apidae, Centridini), J. Insect Behav. 30, 103-118. https://doi. org/10.1007/s10905-017-9600-x.

Seidelmann K. (2014) Behavioural induction of unreceptivity to mating from a post-copulatory display in the red mason bee, Osmia bicornis, Behaviour 151, 1687-1702. https://doi.org/10.1163/1568539X00003213.

Simmons L.W., Alcock J., Reeder A. (2003) The role of cuticular hydrocarbons in male attraction and repulsion by female Dawson's burrowing bee, Amegilla dawsoni, Animal Behav. 66 (4), 677-685.

Toro, H. and Riveros, G. (1998) Comportamiento de cópula de Centris mixta tamarugalis (Hymenoptera: Anthophoridae). Rev. Chilena Ent. 25, 69-75.

Wcislo W.T. (1992) Attraction and learning in matefinding by solitary bees, Lasioglossum (Dialictus) figueresi Wcislo and Nomia triangulifera Vachal (Hymenoptera, Halictidae), Behav. Ecol. Sociobiol. 31, 139-148.

Publisher's note Springer Nature remains neutral with regard to jurisdictional claims in published maps and institutional affiliations. 